\title{
Modular pathway engineering of key precursor supply pathways for lacto- $N$-neotetraose production in Bacillus subtilis
}

\author{
Xiaomin Dong ${ }^{1,4}$, Nan Li ${ }^{2}$, Zhenmin $\mathrm{Liu}^{2}$, Xueqin Lv $\mathrm{v}^{3,4}$, Jianghua $\mathrm{Li}^{3,4}$, Guocheng Du ${ }^{3,4}$, Miao Wang ${ }^{\text {1* }}$
} and Long $\mathrm{Liu}^{3,4^{*}}$

\begin{abstract}
Background: Lacto-N-neotetraose (LNnT) is one of the important ingredients of human milk oligosaccharides, which can enhance immunity, regulate intestinal bacteria and promote cell maturation.

Results: In this study, the synthetic pathway of $L N n T$ was constructed by co-expressing the lactose permease (LacY) $\beta-1,3-N$-acetylglucosaminyltransferase (LgtA) and $\beta$-1,4-galactostltransferase (LgtB) in Bacillus subtilis, resulting in an $\mathrm{LNnT}$ titer of $0.61 \mathrm{~g} / \mathrm{L}$. Then, by fine-tuning the expression level of $\mathrm{LgtB}$, the growth inhibition was reduced and the $\mathrm{LNnT}$ titer was increased to $1.31 \mathrm{~g} / \mathrm{L}$. In addition, by modular pathway engineering, the positive-acting enzymes of the UDP-GICNAc and UDP-Gal pathways were strengthened to balance the two key precursors supply, and the LNnT titer was improved to $1.95 \mathrm{~g} / \mathrm{L}$. Finally, the LNnT titer reached $4.52 \mathrm{~g} / \mathrm{L}$ in a 3-L bioreactor with an optimal glucose and lactose feeding strategy.

Conclusions: In general, this study showed that the LNnT biosynthesis could be significantly increased by optimizing enzymes expression levels and modular pathway engineering for balancing the precursors supply in B. subtilis.
\end{abstract}

Keywords: Lacto-N-neotetraose, Bacillus subtilis, Modular pathway engineering, Human milk oligosaccharides

\section{Background}

As one of the key components of human milk oligosaccharides (HMOs), Lacto- $N$-neotetraose (LNnT) is very beneficial for breast-feeding infant [1], which has the biological functions of enhancing immunity [2], regulating intestinal flora [3-7], and promoting cell maturation [8]. At present, as a potential nutraceutical, LNnT has been approved by the Food and Drug Administration of USA and the European Union to be added to infants and young children foods. LNnT is a linear tetrasaccharide (Gal $\beta 1-4 G l c N A c \beta 1-3 G a l \beta 1-4 G l c)$ consisting

\footnotetext{
*Correspondence: mwang@jiangnan.edu.cn; longliu@jiangnan.edu.cn ${ }^{1}$ Key Laboratory of Food Science and Technology, Ministry of Education, Jiangnan University, Wuxi 214122, China

${ }^{4}$ Key Laboratory of Industrial Biotechnology, Ministry of Education, Jiangnan University, Wuxi 214122, China

Full list of author information is available at the end of the article
}

of D-galactose, $\mathrm{N}$-acetylglucosamine, D-galactose, and D-glucose. Moreover, LNnT is also a core structure of other complex components of breast milk oligosaccharides [9]. These have promoted the growth of the market demand for LNnT. Currently, LNnT can be produced in large scale by chemical synthesis, but the multi-step reactions and expensive raw materials have led to its high price on dairy applications [10]. Compared with chemical synthesis, biosynthesis utilizes only cheap carbon sources and intracellular renewable donors. Therefore, biosynthetic LNnT has attracted the attention of many researchers.

In the previous study, the biosynthetic pathway of LNnT was constructed in Escherichia coli JM109 (the lac $Z$ gene was knocked out) by overexpressing of $\beta-1,3$ $N$-acetylglucosaminyltransferase (LgtA) and $\beta$-1,4galactostltransferase (LgtB) from Nesseria meningitides 
and lactose permease (LacY) [11]. However, the overexpression of LgtA and LgtB severely inhibits the normal growth of cells, which limited the efficient synthesis of LNnT. Moreover, because of the endotoxin content of $E$. coli, it is not the ideal host for producing the additive for infant formula. Unlike E. coli, Bacillus subtilis, a generally regarded as safe (GRAS) host, is highly attractive because of its many excellent characteristics, such as highly efficient protein synthesis system, genetically tractable, various metabolic engineering tools, and easy industrial scale production [12-17]. Thus, B. subtilis has been considered as chassis cell for microbial production of value-added products.

In this study, B. subtilis 168 was selected as the host and the de novo LNnT synthesis pathway was constructed by co-expression of LacY, LgtA, and LgtB. As shown in Fig. 1, UDP- $N$-acetyglucosamine (UDP-GlcNAc) and lactose are catalyzed by LgtA to produce Lacto- $\mathrm{N}$-triose II (LNTII), and then, the LNTII and UDP-galactose (UDP-Gal) are catalyzed into LNnT by LgtB. Therefore, two key factors might affect the efficient synthesis of LNnT: 1) the cell growth inhibited by co-overexpressing of heterologous proteins and 2) the supply of key precursors of UDP-GlcNAc and UDP-Gal. In view of the above problems, we first identified the growth inhibition caused by overexpression of heterologous enzymes, and optimized the expression level of LgtB to alleviate cell growth inhibition, resulting in the increase of LNnT titer to $1.31 \mathrm{~g} / \mathrm{L}$ in shake flasks. Next, the supply of two precursors was further enhanced and balanced by modular pathway engineering, which boosted the LNnT titer from $1.31 \mathrm{~g} / \mathrm{L}$ to 1.95 . Finally, by optimizing the glucose and lactose feeding strategy in a 3-L bioreactor, the LNnT titer increased to $4.52 \mathrm{~g} / \mathrm{L}$, which was 2.3 -fold over that in shake flask. The three strategies used in this study for reducing growth inhibition via optimizing protein expression levels, balancing the precursors supply via modular pathway engineering, and optimization of carbon sources feeding strategy in 3-L bioreactor provide a good start for the effective production of $\mathrm{LNnT}$ in B. subtilis. Moreover, $\mathrm{LNnT}$ was secreted into the fermentation broth, which was convenient for isolation and suitable for industrial production.

\section{Materials and methods}

\section{Microorganisms and cultivation conditions}

Bacillus subtilis 168 strain was used as the initial host. The recombinant $B$. subtilis used in this study are listed in Table 1. E. coli JM109 was used as host for gene cloning. The p7Z6, p7S6, p7C6, p7Z6P43, p7S6P43, p7C6P43, pDG-Cre, and pP43NMK were stored in our laboratory.

Luria-Bertaini (LB) medium was used for all B. subtilis strains and E. coli JM109 cultivation. The shake-flask fermentation medium contained $(\mathrm{g} / \mathrm{L})$ : yeast extract 12 , peptone 6, $\left(\mathrm{NH}_{4}\right)_{2} \mathrm{SO}_{4} 6, \mathrm{~K}_{2} \mathrm{HPO}_{4} \cdot 4 \mathrm{H}_{2} \mathrm{O} 12, \mathrm{KH}_{2} \mathrm{PO}_{4} 2.5$, $\mathrm{MgSO}_{4} \cdot 7 \mathrm{H}_{2} \mathrm{O} 3$, Urea 1.5, and glucose 60.

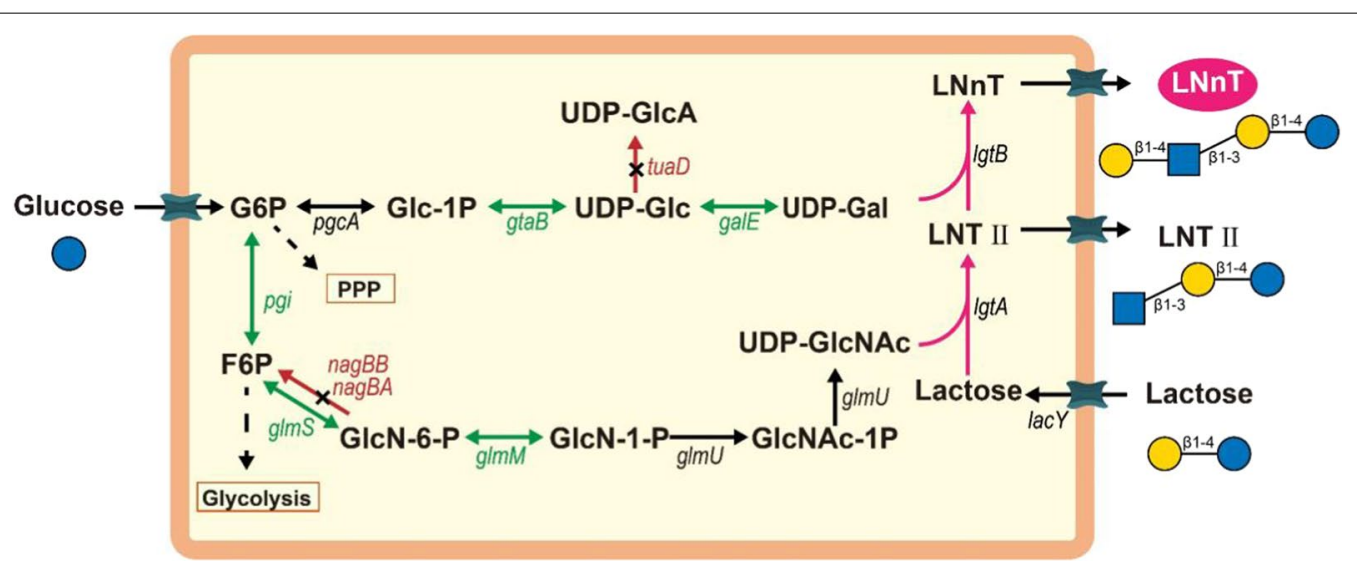

Fig. 1 LNnT biosynthesis model in B. subtilis. black-colored arrows with dash line indicate several steps in the pathway. Green-colored arrows indicate the enhancing expressing of genes. Red-colored arrows indicate the deletion of genes. Pink-colored arrows indicate the construction of LNnT synthesis pathway. PEP, phosphoenolpyruvic acid; Pyr, pyruvate; G6P, glucose-6-phosphate; F6P, fructose-6-phosphate; GlcN-6-P, glucosamine-6-phosphate; GlcN-1-P, glucosamine-1-phosphate; GIcNAc-1P, N-acetylglucosamine-1-phosphate; UDP-GlcNAc, UDP-N-acetyglucosamine; Glc-1P, glucose-1-phosphate; UDP-Glc, UDP-glucose; UDP-GlcA, UDP-glucuronate; UDP-Gal, UDP-galactose; LNTII, Lacto- $N$-triose II; LNnT, Lacto-N-neotetraose. pgi, encoding glucose-6-phosphate isomerase; glmS, encoding glucosamine-6-phosphate synthase; glmM, encoding phosphoglucosamine mutase; glmU, encoding N-acetylglucosamine-1-phosphate uridyltransferase/glucosamine-1-phosphate acetyltransferase; nagBA, encoding glucosamine-6-phosphate deaminase 1; nagBB, encoding glucosamine-6-phosphate deaminase 2; pgcA, encoding phosphoglucomutase; gtaB, encoding UTP-glucose-1-phosphate uridylyltransferase; galE, encoding UDP-glucose 4-epimerase; tuaD, UDP-glucose 6-dehydrogenase; lacY, lactose permease; IgtA, $\beta$-1,3-N-acetylglucosaminyltransferase; IgtB, $\beta$-1,4-galactostltransferase; 0 : Glucose; $\mathrm{N}$-acetylglucosamine; $\mathrm{C}$ : Galactose 
Table 1 Strains and plasmids used in this study

\begin{tabular}{|c|c|c|}
\hline Names & Characteristics & References \\
\hline \multicolumn{3}{|l|}{ Strains } \\
\hline BS168comK & B. subtilis 168 derivate, $P_{x y / A}$-comK & This work \\
\hline BY01 & BS168comK derivate, $\triangle a m y E:: \mathrm{P}_{43}-$ lacY & This work \\
\hline BY02 & BY01 derivate, $\mathrm{P}_{43}-\lg t A, \mathrm{P}_{43}-\lg \mathrm{B}$ & This work \\
\hline BY03 & BY01 derivate/pP43NMK-lgtA-lgtB & This work \\
\hline BY04 & BY01 derivate, $\mathrm{P}_{43}{ }^{-}$-lgtB/pP43NMK-IgtA & This work \\
\hline BY05 & BY04 derivate, $\mathrm{P}_{43}$-lgtB & This work \\
\hline BY06 & BY05 derivate, $\mathrm{P}_{43}$-lgtB & This work \\
\hline BY07 & BY06 derivate, $\mathrm{P}_{43}$-lgtB & This work \\
\hline BY08 & BY06 derivate, $\mathrm{P}_{43}$-pgi & This work \\
\hline BY09 & BY06 derivate, $\mathrm{P}_{43}-\mathrm{g} / \mathrm{mS}$ & This work \\
\hline BY10 & BY06 derivate, $\mathrm{P}_{43}-\mathrm{g} / \mathrm{mM}$ & This work \\
\hline BY11 & BY06 derivate, $\mathrm{P}_{43}-\mathrm{g} / \mathrm{mU}$ & This work \\
\hline BY12 & BY06 derivate, $\triangle$ nag $B A \triangle$ nag $B B: . / 0 \times 72$ & This work \\
\hline BY13 & BY04 derivate, $\mathrm{P}_{43}$-pgi & This work \\
\hline BY14 & BY04 derivate, $\mathrm{P}_{43}-p g c A$ & This work \\
\hline BY15 & BY04 derivate, $\mathrm{P}_{43}-$ gtaB & This work \\
\hline BY16 & BY04 derivate, $\triangle$ tuaD & This work \\
\hline BY17 & BY04 derivate, $\mathrm{P}_{43}$-gale & This work \\
\hline BY18 & BY06 derivate, $\mathrm{P}_{43}$-pgi, $\mathrm{P}_{43}$-gtaB & This work \\
\hline BY19 & BY18 derivate, $\mathrm{P}_{43}-\mathrm{g} / \mathrm{mS}$ & This work \\
\hline $\mathrm{BY} 20$ & BY19 derivate, $\mathrm{P}_{43}-\mathrm{g} / \mathrm{mM}$ & This work \\
\hline BY21 & BY20 derivate, $\triangle$ nag $B A \triangle$ nag $B B:: / 0 \times 72$ & This work \\
\hline BY22 & BY18 derivate, $\mathrm{P}_{43}$-gale & This work \\
\hline $\mathrm{BY} 23$ & BY19 derivate, $\mathrm{P}_{43}$-gale & This work \\
\hline BY24 & BY20 derivate, $\mathrm{P}_{43}$-galE & This work \\
\hline BY25 & BY21 derivate, $\mathrm{P}_{43}$-gale & This work \\
\hline BY26 & BY22 derivate, $\triangle t u a D:: / o x 72$ & This work \\
\hline BY27 & BY23 derivate, $\triangle t u a D:: / o x 72$ & This work \\
\hline BY28 & BY24 derivate, $\triangle t u a D:: / 0 x 72$ & This work \\
\hline BY29 & BY25 derivate, $\triangle t u a D:: / o x 72$ & This work \\
\hline BY30 & BY26 derivate, $\mathrm{P}_{43}-p g c A$ & This work \\
\hline BY31 & $\mathrm{BY} 27$ derivate, $\mathrm{P}_{43}-$ pgcA & This work \\
\hline BY32 & BY28 derivate, $\mathrm{P}_{43}-p g c A$ & This work \\
\hline BY33 & BY29 derivate, $\mathrm{P}_{43}-$ pgcA & This work \\
\hline \multicolumn{3}{|l|}{ Plasmids } \\
\hline pDG-Cre & $\begin{array}{l}\mathrm{Km}^{r} \text {, Amp', temperature sensitive in } B \text {. } \\
\text { subtilis }\end{array}$ & [15] \\
\hline p7Z6 & $\begin{array}{l}\text { pMD18-T containing lox71-zeo-lox66 } \\
\text { cassette }\end{array}$ & [15] \\
\hline $\begin{array}{l}\text { p7S6 } \\
\text { p7C6 }\end{array}$ & $\begin{array}{l}\text { pMD18-T containing lox71-spc-lox66 } \\
\text { cassette } \\
\text { pMD18-T containing lox71-cm-lox66 } \\
\text { cassette }\end{array}$ & $\begin{array}{l}{[15]} \\
{[15]}\end{array}$ \\
\hline p7Z6P43 & p7Z6 containing $P_{43}$ promoter & [22] \\
\hline p7C6P43 & p7C6 containing $\mathrm{P}_{43}$ promoter & {$[22]$} \\
\hline p7S6P43 & p7S6 containing $\mathrm{P}_{43}$ promoter & [22] \\
\hline pP43-lgtA-lgtB & $\begin{array}{l}\text { pP43NMK derivate with } \lg t A \text { and } \lg t B \\
\text { cloned }\end{array}$ & This work \\
\hline pP43-lgtA & pP43NMK derivate with IgtA cloned & This work \\
\hline
\end{tabular}

Shake-flask culture for the production of LNnT: $5 \mathrm{~mL}$ of seed solution cultured for $12 \mathrm{~h}$ in LB was added to baffled $500 \mathrm{~mL}$ shake flask with $45 \mathrm{~mL}$ of fermentation medium. Fermentation conditions are $37{ }^{\circ} \mathrm{C}, 220 \mathrm{rpm}$. $1 \mathrm{~mL}$ samples were taken during fermentation for determining $\mathrm{OD}_{600}$.

\section{Plasmid construction}

The plasmids are listed in Table 1, and all primers are listed in Additional file 1: Table S1. The lgtA (Genbank ID: 904226) and lgtB (Genbank ID: 904227) from Neisseria meningitidis MC58 were codon optimized and synthetized by Nanjing Genscript Biotech Company (Nanjing, china). DNA sequences of the codon-optimized genes are listed in Additional file 1: Tables S2, S3. To construct the $\mathrm{pP} 43 \mathrm{NMK}-\lg t A-\lg t B$ plasmid, the $\lg t A$ gene and $\lg t B$ gene were cloned into pP43NMK plasmid. To construct the pP43NMK-lgtA plasmid, the lgtA gene was cloned into pP43NMK plasmid using the Gibson Assembly Kit (New England Biolabs, NEB).

\section{LNnT biosynthesis pathway construction}

All of the primers used are listed in Additional file 1: Table S1. The Cre/lox system was selected for integration into the genome and gene knockout [18]. The DNA recombination fragment was obtained by overlap extension-PCR, and transformed into B. subtilis by the comK method [19]. The antibiotics including ampicillin $(30 \mu \mathrm{g} /$ $\mathrm{mL})$, kanamycin $(30 \mu \mathrm{g} / \mathrm{mL})$, zeocin $(30 \mu \mathrm{g} / \mathrm{mL})$, chloramphenicol $(5 \mu \mathrm{g} / \mathrm{mL})$, and spectinomycin $(50 \mu \mathrm{g} / \mathrm{mL})$ were used for selections.

The original promoter of the comk gene was replaced with a xylose-inducible promoter $\mathrm{P}_{x y l A}$ from the strain B. subtilis 168, yielding the strain BS168comk. lacY gene from E. coli $\mathrm{K} 12$ was integrated into the genome of BS168comk, yielding that the strain BY01. $\operatorname{lgt} A$ and $\operatorname{lgtB}$ genes were integrated into the genome of BY01, producing the strain BY02. Plasmid pP43NMK-lgtA-lgtB was transformed into BY01, yielding the strain BY03. One, two, three, and four copies of $\lg t B$ were integrated into the genome and plasmid pP43NMK-lgtA was transformed into BY01, yielding the strain BY04, BY05, BY06, and BY07, respectively. The genomic loci of lgtA and $\lg t B$ genes integration expression are listed in Additional file 1: Tables S4-S8.

\section{Knockout of tuaD, nagBA, nagBB, overexpression of $p g c A$, gtaB, galE, pgi, glmS, glmM, glmU}

To accelerate the conversion between intermediate metabolites in the UDP-Gal precursor pathway, $p g c A$ encoding phosphoglucomutase, gtaB encoding UTP-glucose-1-phosphate uridylyltransferase, and galE encoding UDP-glucose 4-epimerase were overexpressed under the 
control of $\mathrm{P}_{43}$ promoter. To block the conversion of UDPGlc to UDP-glucuronate, tuaD encoding UDP-glucose 6-dehydrogenase was deleted. To enhance the conversion between intermediate metabolites in the UDP-GlcNAc precursor pathway, pgi encoding glucose-6-phosphate isomerase, $g \operatorname{lm} S$ encoding glucosamine-6-phosphate synthase, $\operatorname{glm} M$ encoding phosphoglucosamine mutase, and $g \operatorname{lm} U$ encoding $N$-acetylglucosamine-1-phosphate uridyltransferase/glucosamine-1-phosphate acetyltransferase were overexpressed under the control of $\mathrm{P}_{43}$ promoter. To block the conversion of GlcN-6-P to F6P, nagBA encoding glucosamine-6-phosphate deaminase 1 and $n a g B B$ encoding glucosamine-6-phosphate deaminase 2 were simultaneously knocked out. The genomic loci of $p g c A, g t a B, g a l E, p g i, g l m M$, and $g \operatorname{lm} U$ genes integration expression are listed in Additional file 1: Tables S9-S14. The constructed strains BY08-BY17 and BY18BY33 are listed in Table 1.

\section{Microbial production of LNnT in 3-L bioreactor}

The production of LNnT by batch culture of BY28 strain was performed with the optimized fermentation medium containing: $30 \mathrm{~g} / \mathrm{L}$ glucose, $1.8 \mathrm{~g} / \mathrm{L}$ lactose, $20 \mathrm{~g} / \mathrm{L}$ yeast extract, $20 \mathrm{~g} / \mathrm{L}$ tryptone, $8 \mathrm{~g} / \mathrm{L}$ urea, $12.5 \mathrm{~g} / \mathrm{L} \mathrm{K} \mathrm{HPO}_{4} \cdot 3 \mathrm{H}_{2} \mathrm{O}, 2.5 \mathrm{~g} / \mathrm{L} \mathrm{KH}_{2} \mathrm{PO}_{4}$, and $10 \mathrm{~mL} / \mathrm{L}$ trace metal solution. The trace metal solution contained $4 \mathrm{~g} / \mathrm{L} \mathrm{FeSO}_{4} \cdot 7 \mathrm{H}_{2} \mathrm{O}, 4 \mathrm{~g} / \mathrm{L} \mathrm{CaCl}, 1 \mathrm{~g} / \mathrm{L} \mathrm{MnSO}_{4} \cdot 5 \mathrm{H}_{2} \mathrm{O}$, $0.4 \mathrm{~g} / \mathrm{L} \mathrm{CoCl}_{2} \cdot 6 \mathrm{H}_{2} \mathrm{O}, 0.2 \mathrm{~g} / \mathrm{L}$ NaMoO $4 \cdot 2 \mathrm{H}_{2} \mathrm{O}, 0.2 \mathrm{~g} / \mathrm{L}$ $\mathrm{ZnSO}_{4} \cdot 7 \mathrm{H}_{2} \mathrm{O}, 0.1 \mathrm{~g} / \mathrm{L} \mathrm{AlCl}_{3} \cdot 6 \mathrm{H}_{2} \mathrm{O}, 0.1 \mathrm{~g} / \mathrm{L} \mathrm{CuCl} \mathrm{Cu}_{2} \mathrm{O}$, and $0.05 \mathrm{~g} / \mathrm{L} \mathrm{H}_{3} \mathrm{BO}_{4}$. The feeding solution contained $500 \mathrm{~g} / \mathrm{L}$ glucose and $30 \mathrm{~g} / \mathrm{L}$ lactose. $180 \mathrm{~mL}$ of seed culture that was cultured in $1 \mathrm{~L}$ shake flasks for $12 \mathrm{~h}$ was added into a 3-L fermentor (BioFlo 115, New Brunswick Scientific Co., Edison, NJ, USA) containing initial 1.62 $\mathrm{L}$ of fermentation medium. Agitation was provided by 2 6-bladed disk turbines. The $\mathrm{pH}$ was automatically kept at 7.0 via the addition $14 \% \mathrm{NH}_{3} \cdot \mathrm{H}_{2} \mathrm{O}$, the temperature was maintained at $37{ }^{\circ} \mathrm{C}$, and the aeration rate and agitation speed were $1.0 \mathrm{vvm}$ and $800 \mathrm{rpm}$, respectively.

In the intermittent feeding fermentation, whenever the residual glucose concentration was lower than $5 \mathrm{~g} / \mathrm{L}$, the feeding solution of glucose and lactose was added to the bioreactor to restore the glucose concentration to about $30 \mathrm{~g} / \mathrm{L}$. In the dual-flow continuous feeding strategy with control of glucose concentration, the glucose concentration was maintained at $10-20 \mathrm{~g} / \mathrm{L}$ via adjusting the feeding rates based on the concentration of residual glucose in the bioreactor.

\section{Analytic methods}

Samples were centrifuged at $14,000 \times g$ for $5 \mathrm{~min}$. The supernatant was diluted 10 times with $\mathrm{ddH}_{2} \mathrm{O}$ after removing the protein by the sevage method, and the sevage solvent was replaced by chloroform/n-butanol (4:1 $\mathrm{v} / \mathrm{v}$ ) [20]. The concentrations of LNTII, LNnT, and lactose were measured by high-performance anion-exchange chromatography-pulsed amperometric detection (HPEAC-PAD) using a CarboPac PA10 $(4 \times 250 \mathrm{~mm})$ column. The mobile phase was $\mathrm{NaOH}(36 \mathrm{mM})$ at a flow rate of $1.00 \mathrm{~mL} / \mathrm{min}$ and $30^{\circ} \mathrm{C}$. The injection volume was $25 \mu \mathrm{L} . \mathrm{OD}_{600}$ was converted to dry cell weight (DCW) according to the following equation: $1 \mathrm{OD}_{600}=0.35 \mathrm{~g} / \mathrm{L}$. The glucose concentration was measured using a glucose-glutamate analyzer (SBA-40C; Biology Institute of Shandong Academy of Sciences). All experiments were independently done at least three times and the statistical analyses were performed using the one-way ANOVA.

\section{Results and discussion}

\section{Design and construction of LNnT biosynthesis pathway}

We chose B. subtilis 168 as the initial strain. To improve the efficiency of transforming plasmids or integration cassettes, the original promoter of the comk gene was replaced with a xylose-inducible promoter, generating strain BS168comK [19]. Then, $\beta$-galactoside permease gene $(\mathrm{lac} Y)$ from $E$. coli $\mathrm{K} 12$ was inserted into the genome and overexpressed using the strong constitutive promoter $\mathrm{P}_{43}$ for transporting the precursor lactose into B. subtilis. In the biosynthesis pathway in vivo, enzymes with effective catalytic capabilities are crucial for efficient production of LNnT. Considering that $\operatorname{lgt} A$ gene encoding $\beta-1,3-N$-acetylglucosaminyltransferase and $\lg t B$ gene encoding $\beta$-galactostltransferase from Neisseria meningitidis are known to have catalytic activity for LNnT synthesis $[11,21]$, we chose to introduce these two enzymes to construct $\mathrm{LNnT}$ synthesis pathway.

Overexpression of key enzymes can improve catalytic activity; however, overexpression of protein may lead to growth inhibition and thus decrease synthesis efficiency [22]. Therefore, to reduce growth inhibition, optimizing the amount of heterologous proteins expression may be an ideal method. To identify the optimal expression of LgtA and LgtB, we tested the two key enzymes' expression level via integrating different copy numbers or expressing on plasmid in engineered $B$. subtilis. The pathway for de novo LNnT biosynthesis was constructed by co-expressing LgtA and LgtB under the control of strong constitutive promoter $\mathrm{P}_{43}$ using integration expression system or pP43NMK plasmid, yielding BY02 and BY03, respectively. The titer of LNTII in BY02 and BY03 was both below detection level, which suggested that the high expression level of LgtA was still insufficient for LNnT synthesis (Fig. 2a). Therefore, the expression of LgtA in the pP43NMK plasmid system (high level) is more suitable for LNnT synthesis. Compared with controlling the expression of LgtB at the low level (strain BY02), the 

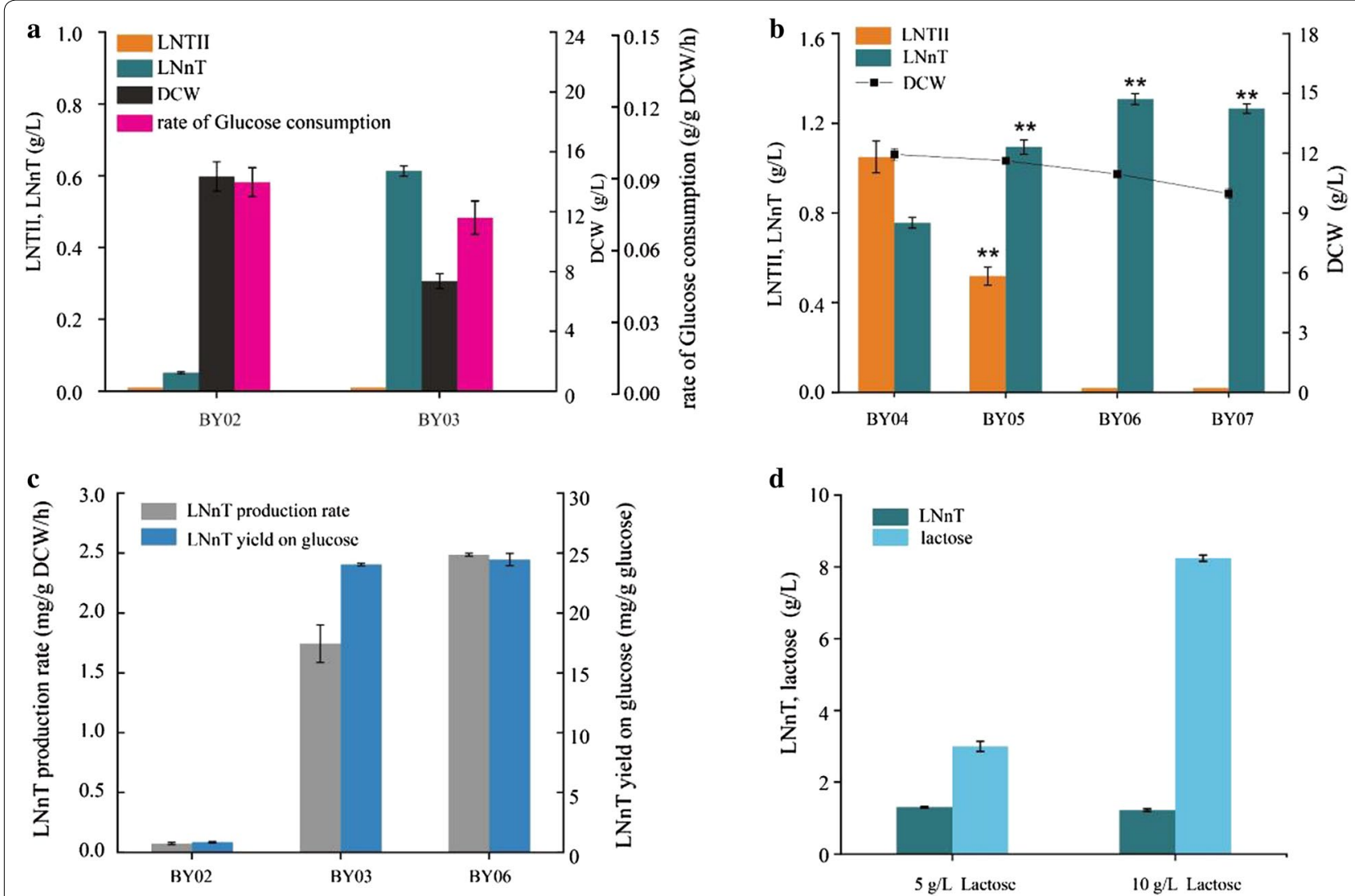

Fig. 2 Effects of different expression levels of IgtA and lgtB genes. a LNTII, LNnT titer of BYO2 and BY03, DCW and rate of glucose consumption in BY02 and BY03; $\mathbf{b} L N T I I, L N n T$ titer of BY04-BY07, and DCW in BY04-BY07, the ${ }^{* *}$ mean $p<0.01 ; \mathbf{c} L N n T$ production rate, and yield on glucose in $\mathrm{BY} 02$, BYO3 and BY04; d LNnT titer and lactose concentration of BY06, when cultivated with $5 \mathrm{~g} / \mathrm{L}$ lactose and $10 \mathrm{~g} / \mathrm{L}$ lactose. Triplicate experiments were done, and error bars represent the standard deviation

LNnT titer increased significantly by 12.2 fold to $0.61 \mathrm{~g} / \mathrm{L}$ (strain BY03) when the expression of LgtB was increased to the highest level. However, compared with strain BY02 $(\mathrm{DCW}=14.35 \mathrm{~g} / \mathrm{L}, 0.087 \mathrm{~g} / \mathrm{g} \mathrm{DCW} / \mathrm{h})$, the maximum $\mathrm{DCW}$ value and glucose consumption rate of the BY03 strain $(\mathrm{DCW}=7.35 \mathrm{~g} / \mathrm{L}, 0.073 \mathrm{~g} / \mathrm{g} \mathrm{DCW} / \mathrm{h})$ were significantly reduced by $48.8 \%$ and $16.1 \%$, respectively (Fig. $2 a$ ). We speculated that the co-overexpressed heterologous protein LgtB and LgtA arrested normal cell growth. To confirm our speculation, the expression level of LgtB was changed via integrating different copies $(n=1,2,3,4)$ in the genome under $\mathrm{P}_{43}$ promoter, while the LgtA was expressed using the $\mathrm{PP} 43 \mathrm{NMK}$ plasmid, yielding strains BY04, BY05, BY06, and BY07, respectively. Compared with strain BY04, BY05, and BY07, the titer of LNnT in strain BY06 was the highest and the most of LNT II in BY06 was converted to LNnT (Fig. 2b).

In this study, under the premise that LgtA must be overexpressed, the growth of cells was successfully restored by optimizing LgtB expression to an appropriate level, and the DCW raised from $7.35 \mathrm{~g} / \mathrm{L}$ (strain BY03) to $11 \mathrm{~g} / \mathrm{L}$ (strain BY06), and the titer of LNnT increased by $114.8 \%$ to $1.31 \mathrm{~g} / \mathrm{L}$. Furthermore, the LNnT yield on glucose $(24.4 \mathrm{mg} / \mathrm{g}$ glucose $)$ and the production rate $(2.5 \mathrm{mg} / \mathrm{g} \mathrm{DCW} / \mathrm{h})$ of strain BY06 were both higher than that of strain BY02 and BY03 (Fig. 2c). When the amount of lactose added to the fermentation medium increased from $5 \mathrm{~g} / \mathrm{L}$ to $10 \mathrm{~g} / \mathrm{L}$, the yield of $\mathrm{LNnT}$ in the strain BY06 did not further increase, suggesting that the supply of lactose was sufficient when the amount of lactose was $5 \mathrm{~g} / \mathrm{L}$ (Fig. 2d). However, the extracellular LNT II was below detection level in the strain BY06, so we speculated that intracellular precursors might limit efficient LNnT synthesis due to its insufficient supply.

\section{Design and construction of the UDP-GICNAC and UDP-Gal supply module}

In our previous study, the titer of hyaluronic acid was greatly increased by simultaneously increasing two precursors, UDP-glucuronate (UDP-GlcA) and UDP-GlcNAc via overexpressing the enzymes in the precursors' synthesis pathways [23]. Therefore, next, we focus on 
how to improve and balance the supply of two precursors UDP-GlcNAc and UDP-Gal for LNnT synthesis. The precursors UDP-Gal and UDP-GlcNAc are derived from glucose 6-phosphate and fructose 6-phosphate of Embden-Meyerhof-Parnas pathway (EMP), respectively. Modular pathway engineering divides complex synthetic networks into modules, systematically strengthens and balances the various modules to optimize the entire metabolic network via assembling different strengths between modules $[24,25]$. Therefore, modular pathway engineering can be used as an effective strategy to balance the UDP-GlcNAc and UDP-Gal supply for LNnT synthesis. In this work, we divided the LNnT biosynthetic pathway into the UDP-GlcNAc and UDP-Gal supply modules.

We attempted to identify positive-acting enzymes in the UDP-GlcNAc and UDP-Gal pathways by enhancing related gene expression through adding one copy in the genome under $\mathrm{P}_{43}$ promoter or blocking relevant gene expression. Specifically, the original promoter of $g \operatorname{lm} S$ gene was replaced with $\mathrm{P}_{43}$ promoter. Specifically, the UDP-GlcNAc supply module contained $p g i$ (encoding glucose-6-phosphate isomerase), glmS (encoding glucosamine-6-phosphate synthase), glmM (encoding phosphoglucosamine mutase), $g \operatorname{lm} U$ (encoding $\mathrm{N}$-acetylglucosamine-1-phosphate uridyltransferase/ glucosamine-1-phosphate acetyltransferase), nagBA (encoding glucosamine-6-phosphate deaminase 1), and $n a g B B$ (encoding glucosamine-6-phosphate deaminase 2). The UDP-Gal synthesis pathway included $p g c A$ (encoding phosphoglucomutase), gtaB (encoding UTPglucose-1-phosphate uridylyltransferase), galE (encoding UDP-glucose 4-epimerase), and tuaD (UDP-glucose 6-dehydrogenase). We verified the effect of Pgi in the two modules, as Pgi is a bidirectional enzyme that can also convert fructose 6-phosphate to glucose 6-phosphate.

To verify the positive-acting enzyme in the UDP-GlcNAc module, the UDP-GlcNAc precursor-deficient strain BY06 was engineered. As shown in Fig. 3c, the titer of LNnT increased from $1.31 \mathrm{~g} / \mathrm{L}$ (BY06) to $1.42 \mathrm{~g} / \mathrm{L}$ (BY09, overexpression of $g \operatorname{lm} S$ gene), $1.45 \mathrm{~g} / \mathrm{L}$ (BY10, overexpression of $\operatorname{glm} M$ gene), and $1.47 \mathrm{~g} / \mathrm{L}$ (BY12, knocking out of $n a g B A$ and $n a g B B$ genes), respectively. The up-regulation of $g \operatorname{lm} S$ and $g \operatorname{lm} M$ and co-deletion of $n a g B A$ and $n a g B B$

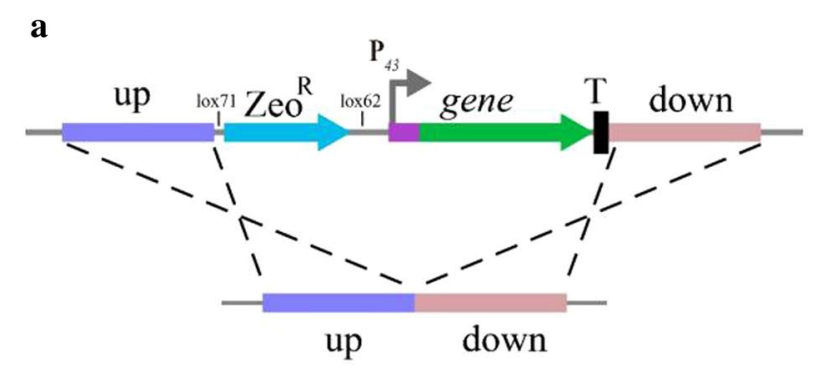

b
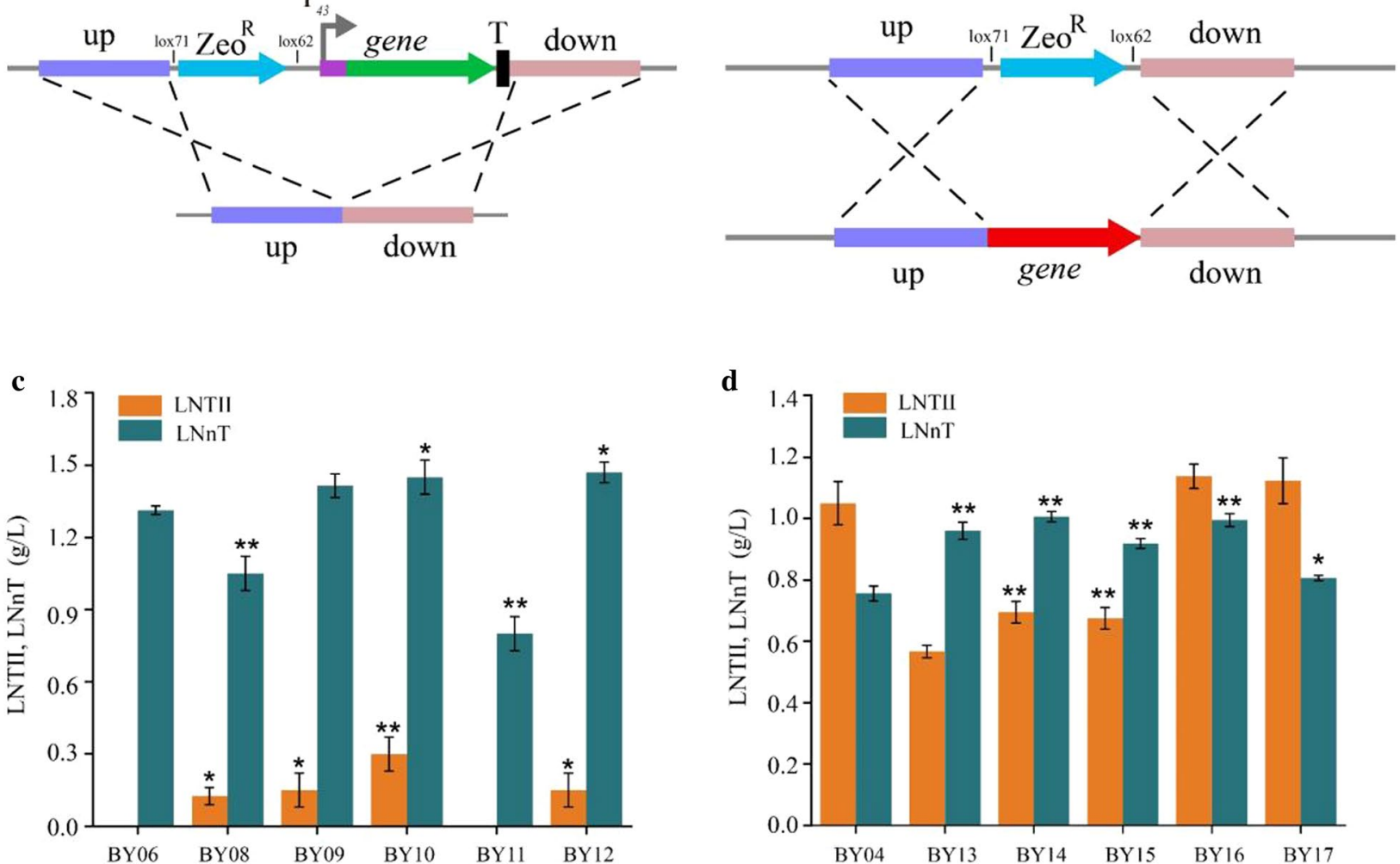

Fig. 3 Identifying positive-acting enzymes in the UDP-GICNAC and UDP-Gal pathways. a Schematic of the cassette used to overexpress gene in $B$. subtilis. b Schematic of the cassette used to knockout gene in B. subtilis. c LNTII, LNnT titer of BY08 BY12 and the control host BY06. d LNTII, LNnT titer of BY13-BY17 and the control host BY04. Triplicate experiments were done, and error bars represent the standard deviation. * and ${ }^{* *}$ mean $p<0.05$ and $p<0.01$, respectively 
in the branch pathways demonstrated that the conversion of F6P to GlcN-6-P (glucosamine-6-phosphate) and then to GlcN-1-P (glucosamine-1-phosphate) was the rate-limiting step for LNnT synthesis. The titer of LNTII increased to $0.13 \mathrm{~g} / \mathrm{L}$, while the titer of LNnT decreased to $1.05 \mathrm{~g} / \mathrm{L}$ in BY08 (overexpression of $p g i$ gene), indicating that up-regulation of $p g i$ can lead to glucose flowing to UDP-GlcNAc synthetic pathway in BY06. However, the titer of LNnT was reduced by $38.9 \%$ in BY11 (overexpression of $g \operatorname{lm} U$ gene), so we guessed that the overexpression of $g \operatorname{lm} U$ was not suitable for the enhancement of the UDP-GlcNAc pathway in the LNnT-producing strain. The BY04 strain was used as the host for confirming ratelimiting enzymes in the UDP-Gal module. The titer of LNnT increased from $0.76 \mathrm{~g} / \mathrm{L}$ (BY04) to $1.01 \mathrm{~g} / \mathrm{L}$ (BY14, overexpression of $p g c A$ gene), $0.92 \mathrm{~g} / \mathrm{L}$ (BY15, overexpression of $g t a B$ gene), $1.0 \mathrm{~g} / \mathrm{L}$ (BY16, knocking out tuaD gene), and $0.81 \mathrm{~g} / \mathrm{L}$ (BY17, overexpression of galE gene). In the strain BY13 (overexpression of pgi gene in BY04), the titer of LNnT increased by $26.3 \%(0.96 \mathrm{~g} / \mathrm{L})$ compared with control strain BY04, whereas LNnT production decreased in the BY08 strain (overexpression of pgi gene in BY06), indicating that the Pgi was an effective enzyme in LNnT synthetic pathway. These results demonstrated that the insufficient supply of the two precursors was indeed the rate-limiting step in the synthesis of LNnT and also showed that the overexpression of the positiveacting enzymes in the biosynthetic pathways or deletion of the enzymes in the branching pathways would lead to the increase in production.

The $p g i, g \operatorname{lm} S, g \operatorname{lm} M, n a g B A$, and $n a g B B$ gene of UDPGlcNAc pathway, and $p g c A$, gtaB, tuaD, and galE gene of UDP-Gal pathway were selected for modular engineering to improve the titer of LNnT. The UDP-GlcNAc module engineering was conducted into four different strength levels via combinatorial modulation of overexpression of $p g i, g \operatorname{lm} S, g \operatorname{lm} M$ and co-deletion of $n a g B A, n a g B B$ (Fig. 4a). Meanwhile, the UDP-Gal module engineering was also designed into four different levels of strength by assembling of overexpression of $p g c A, g t a B, g a l E$, and tuaD knockout (Fig. 4b). Next, the various strengths of the UDP-Gal and UDP-GlcNAc modules were assembled to obtain 16 strains, as shown in Fig. 4c.

\section{Effects of UDP-GIcNAc and UDP-Gal supply module on LNnT biosynthesis}

The effects of various combinations of UDP-Gal and UDP-GlcNAc supply modules were compared in strain BY18-BY33 in shake-flask fermentation (Fig. 4c). When the UDP-Gal module was kept at a low level, the increased strength of the UDP-GlcNAc module from low to medium, medium-plus, and high level resulted in an increase in LNTII production to $0.1 \mathrm{~g} / \mathrm{L}, 0.5 \mathrm{~g} / \mathrm{L}$, and $0.8 \mathrm{~g} / \mathrm{L}$ (strains BY19, BY20, and BY21), comparing to below detection level (strain BY18). Similarly, when the UDP-Gal module was at a medium-plus level, the UDP-GlcNAc module increased from low to medium, medium-plus, and high level resulted in $43.3 \%(0.86 \mathrm{~g} / \mathrm{L})$, 98.3\% (1.19 g/L), and 166.7\% (1.6 g/L) increase in LNTII titer (strains BY27, BY28, and BY29). These results indicated that the supply of intracellular UDP-GlcNAc was deficient when UDP-GlcNAc module was kept at a low strength, and strengthen the level of UDP-GlcNAc module could effectively promote LNTII synthesis. Compared with controlling the UDP-GlcNAc module at medium-plus level and the UDP-Gal module at low level $(1.29 \mathrm{~g} / \mathrm{L}$, strain BY20), the titer of LNnT increased by $2.3 \%$ and $51.2 \%(1.32 \mathrm{~g} / \mathrm{L}$, strain BY24and $1.95 \mathrm{~g} / \mathrm{L}$, strain BY28) when the UDP-Gal module level was increased to medium and medium-plus levels. The results indicated that the concentration of intracellular UDP-Gal was significantly low when UDP-Gal module was kept at a low strength.

As shown in Fig. 4c, improving the UDP-Gal module at medium-plus strength and the UDP-GlcNAc module at low level resulted in almost no increase in the titer of LNTII $(0.6 \mathrm{~g} / \mathrm{L})$ and $3.8 \%(1.30 \mathrm{~g} / \mathrm{L})$ decrease in the titer of LNnT in the strain BY26, compared with the case when UDP-Gal module was at a medium level and the UDP-GlcNAc module still at low level with LNTII $(0.56 \mathrm{~g} / \mathrm{L})$ and LNnT $(1.35 \mathrm{~g} / \mathrm{L})$ in the strain BY22. On the basis of the strain BY26, the module strength of UDP-Gal was further increased to high level, which in turn resulted in a $23.1 \%$ decrease in LNnT titer $(1.0 \mathrm{~g} / \mathrm{L}$, strain BY30). These results showed that UDP-Gal supply in strain BY26 was not a rate-limiting step, so when the UDP-Gal module was further strengthened, the titer was reduced due to the imbalance of the two modules. Conversely, when the module strength of UDP-GlcNAc was increased to medium strength based on strain BY26, LNTII titer increased by $43.3 \%(0.86 \mathrm{~g} / \mathrm{L})$ and LNnT titer increased by $34.6 \%(1.75 \mathrm{~g} / \mathrm{L})$ in the strain BY27. Strengthening the UDP-GlcNAc module led to a significant increase in titer, indicating that the balance of UDP-GlcNAc and UDP-Gal supply was critical to the efficient synthesis of $\mathrm{LNnT}$, which was achieved through module engineering strategy.

In summary, compared with control strain BY06, the LNnT titer was significantly improved by both controlling the UDP-Gal and UDP-GlcNAc modules at medium-plus levels (strain BY28), the LNnT yield on glucose increased by $33.2 \%$ (32.5 $\mathrm{mg} / \mathrm{g}$ glucose), and LNnT production rate increased by $23.3 \%(3.07 \mathrm{mg} / \mathrm{g} \mathrm{DCW} / \mathrm{h})$, respectively, resulting in a maximal titer of $1.95 \mathrm{~g} / \mathrm{L}$ LNnT at $48 \mathrm{~h}$ (Fig. 5a). After enhancing the synthetic pathway of the two precursors, the maximum DCW of 


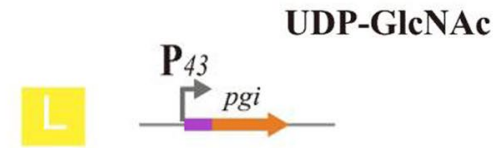

M

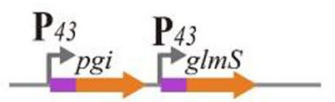

$\mathrm{M}^{+}$

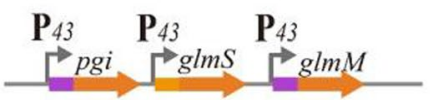

$\mathrm{H}$

c

$\mathbf{P}_{43} \quad \mathbf{P}_{43} \quad \mathbf{P}_{43} \quad \mathbf{P}_{\text {ori }} \mathbf{P}_{\text {ori }}$

$\longrightarrow$ pgi $\longrightarrow$ glmS $\longrightarrow \operatorname{glm} M \longrightarrow$ nagBA $\longmapsto$ nagBB b

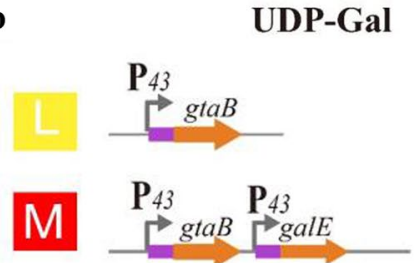

$\mathrm{M}^{+}$

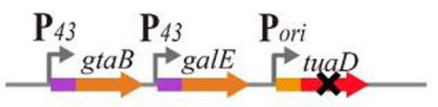

$\mathrm{H}$

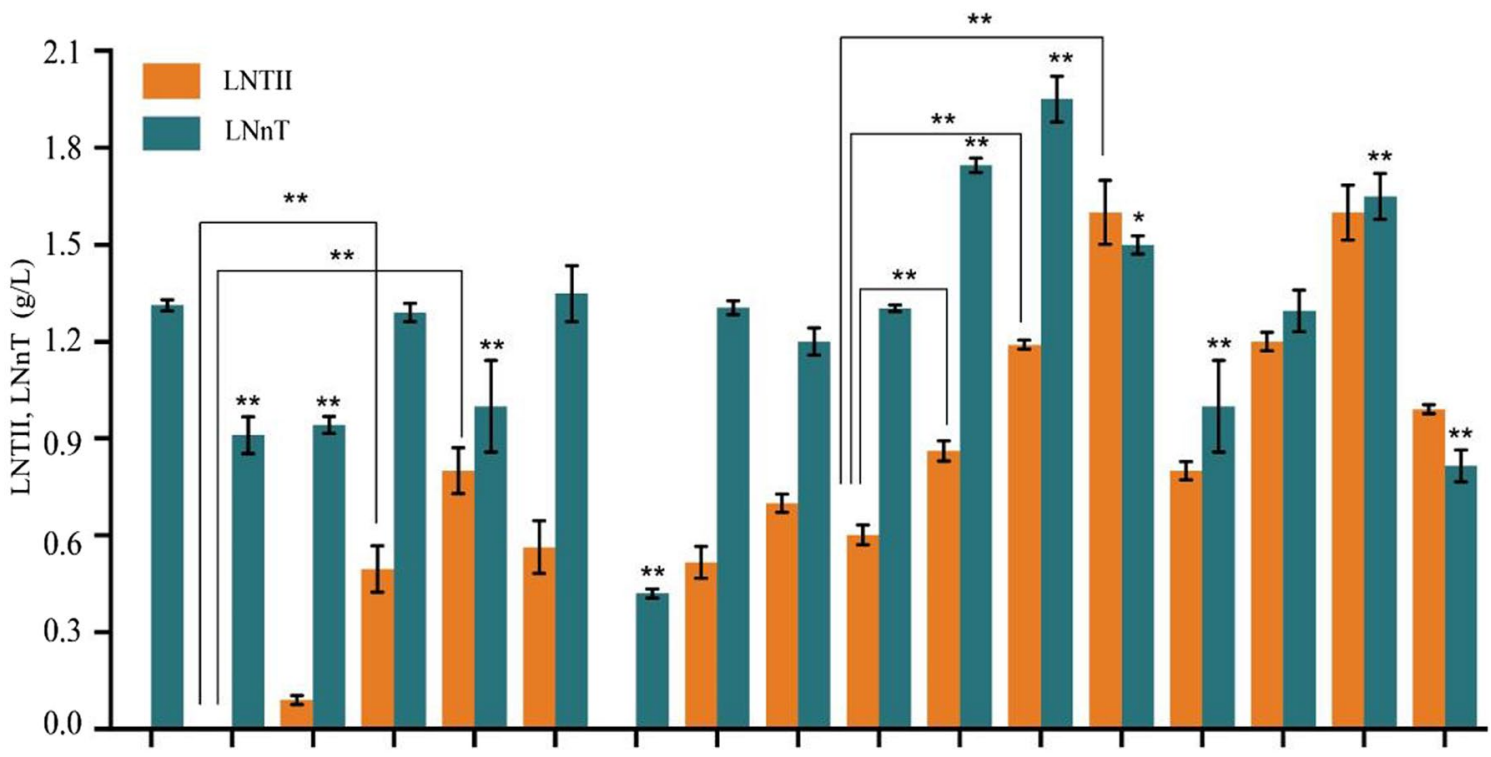

UDP-Gal

UDP-GlcNAc

$\mathrm{ck}$

M

M

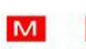

$\mathrm{M}$
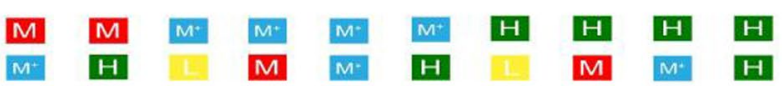

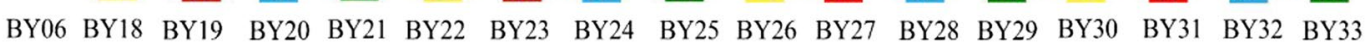

Fig. 4 Effects of UDP-GlcNAc and UDP-Gal supply module on LNnT biosynthesis. a Four strengthen levels of UDP-GlcNAc module. $\mathbf{b}$ Four strengthen levels of UDP-Gal module. $\mathbf{c}$ Influences of modular engineering of LNnT and LNTII. Triplicate experiments were done, and error bars represent the standard deviation. * and ${ }^{* *}$ mean $p<0.05$ and $p<0.01$, respectively

strain BY28 increased to $13.2 \mathrm{~g} / \mathrm{L}$, which was $20 \%$ higher than that of strain BY06 (Fig. 5b). These results suggested that the supply and balance of the two precursors by module pathway engineering are critical for efficient production of LNnT. Noticeably, the accumulation of extracellular LNT II $(1.19 \mathrm{~g} / \mathrm{L})$ in BY28 strain indicated that the catalytic ability of LgtB enzyme in BY28 may be insufficient. Unfortunately, increasing the expression level of LgtB may cause the pressure of cellular protein synthesis system to reduce LNnT synthesis efficiency. Therefore, improving the catalytic efficiency of key enzyme LgtB by engineering strategy will be an effective method to improve the synthesis efficiency of LNnT, such as enzyme protein engineering, enzyme evolution, and flow cytometry efficient screening, and phage-assisted continuous evolution [26, 27].

\section{Production of $\mathrm{LNnT}$ by BY28 in a 3-L bioreactor}

Based on the results of the modular engineering strategy, the engineered B. subtilis BY28 was used for LNnT production in a 3-L bioreactor by two feeding strategies. The LNnT titer with the time course under the intermittent feeding strategy and dual-flow continuous feeding strategy with control of glucose and lactose concentration is 


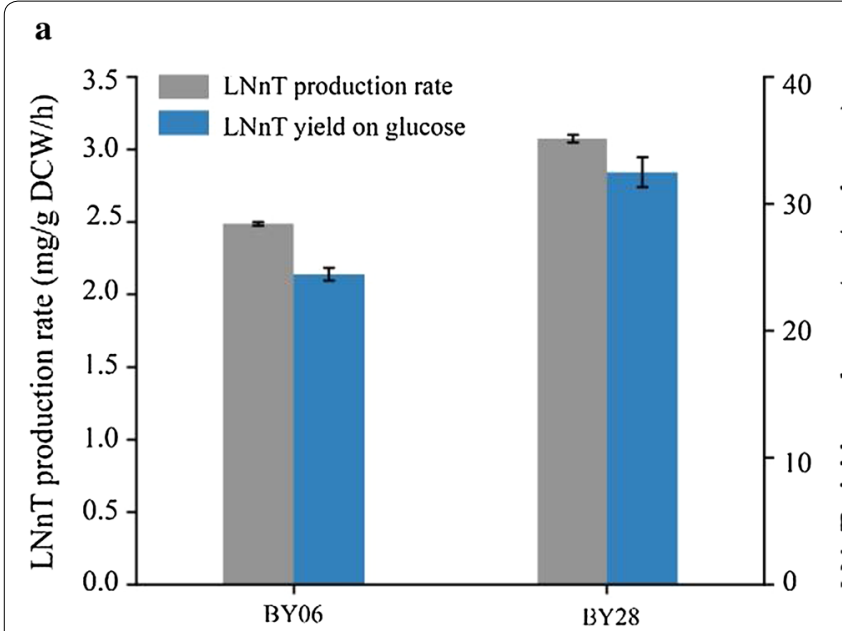

b

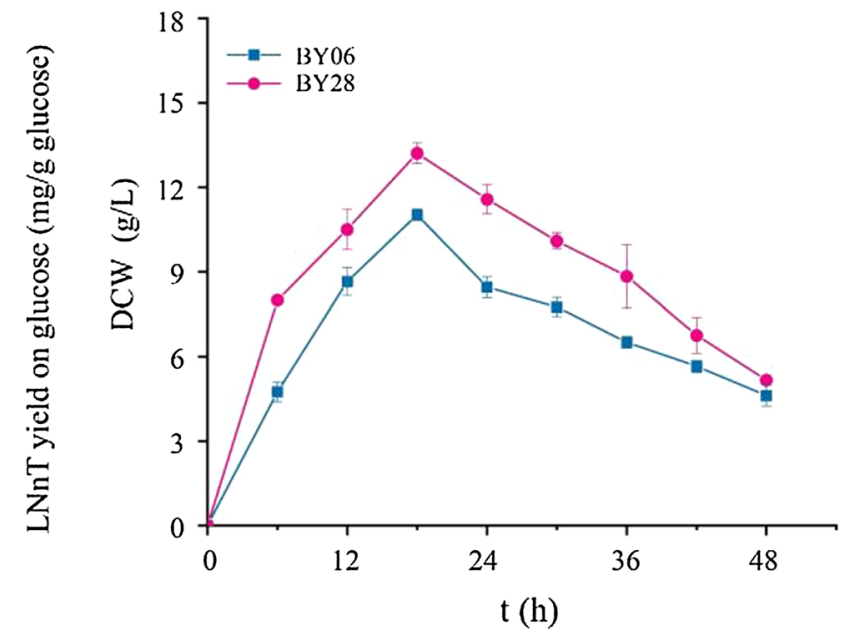

$\mathrm{t}(\mathrm{h})$

Fig. 5 Effects of modular engineering on LNnT biosynthesis. a LNnT production rate, and yield on glucose in BY06 and BY28. b Comparison of cell growth of BY06 and BY28

shown in Fig. 6a, b, respectively. In intermittent feeding fermentation, a total of $220 \mathrm{~mL}$ of glucose and lactose feeding solution was added to the 3 - $\mathrm{L}$ fermentor during the $72 \mathrm{~h}$ of culture period, the maximum DCW was $14.5 \pm 0.22 \mathrm{~g} / \mathrm{L}$, and the titer of LNnT and LNT II were $3.68 \pm 0.15 \mathrm{~g} / \mathrm{L}$ and $1.77 \pm 0.11 \mathrm{~g} / \mathrm{L}$, respectively. The LNnT yield on glucose and the production rate was $40.4 \pm 0.13 \mathrm{mg} / \mathrm{g}$ and $3.52 \pm 0.061 \mathrm{mg} / \mathrm{g} \mathrm{DCW} / \mathrm{h}$, respectively. In dual-flow continuous feeding fermentation, a total of $310 \mathrm{~mL}$ of glucose and lactose feeding solution was added to the 3-L fermentor during the $72 \mathrm{~h}$ of culture period, the maximum $\mathrm{DCW}$ was $14.7 \pm 0.31 \mathrm{~g} / \mathrm{L}$, and the titer of LNnT and LNT II were $4.52 \pm 0.21 \mathrm{~g} / \mathrm{L}$ and $2.64 \pm 0.15 \mathrm{~g} / \mathrm{L}$, respectively. The $\mathrm{LNnT}$ yield on glucose and the production rate were $41.9 \pm 0.17 \mathrm{mg} / \mathrm{g}$ and $4.27 \pm 0.055 \mathrm{mg} / \mathrm{g} \mathrm{DCW} / \mathrm{h}$, respectively. These results showed that high concentrations of glucose and lactose in the fermentation broth result in reduced host synthesis efficiency of LNnT. Therefore, dual-flow continuous feeding strategy with control of glucose and lactose concentration was more suitable for LNnT production, and this might be useful for the scale-up of LNnT production. The total titer of LNnT $(4.52 \mathrm{~g} / \mathrm{L})$ and LNTII $(2.64 \mathrm{~g} / \mathrm{L})$ of BY28 was $7.16 \mathrm{~g} / \mathrm{L}$ in the $3-\mathrm{L}$ bioreactor, which was higher than the total titer of LNnT and its derivate $(5 \mathrm{~g} / \mathrm{L})$ of $E$. coli JM109 in the 2-L reactor. Moreover, LNnT could be released in the extracellular medium by B. subtilis, but could not by E. coli JM109 [11].
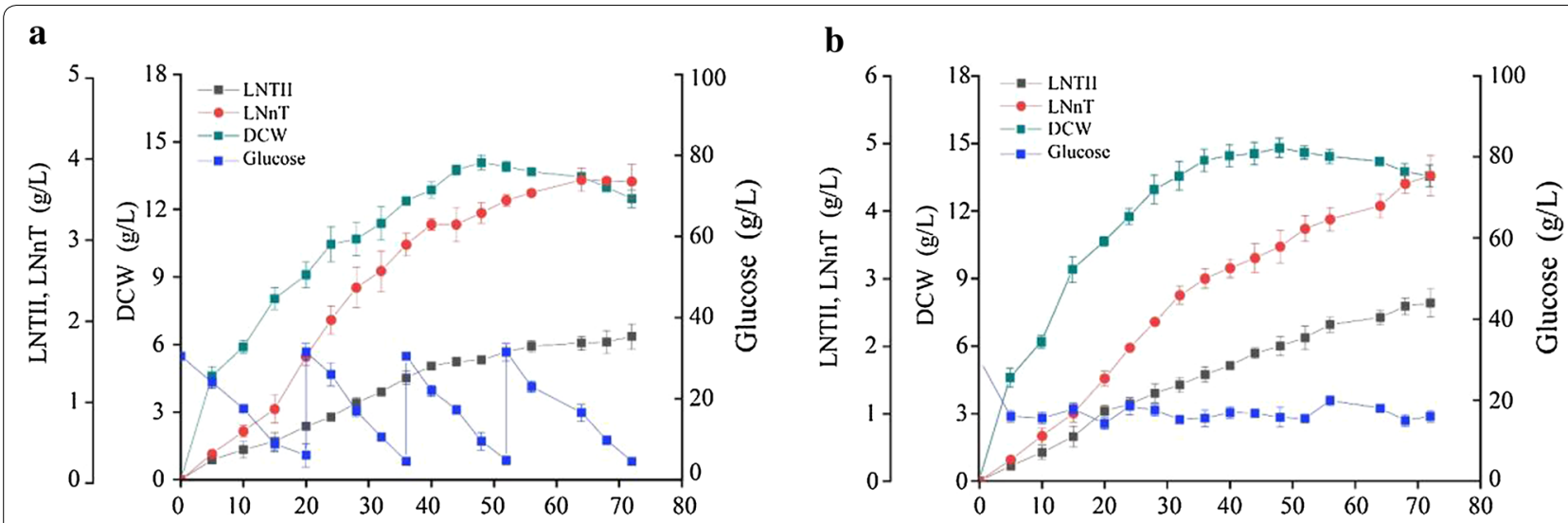

Fig. 6 Production of LNnT by BY28 in a 3-L bioreactor. a Time course of the LNnT production in intermittent feeding fermentation. $\mathbf{b}$ Time course of the LNnT production in dual-flow continuous feeding fermentation. Triplicate experiments were done, and error bars represent the standard deviation 
Therefore, the B. subtilis was more suitable for industrial production of LNnT than E. coli JM109 because of convenient isolation.

\section{Conclusion}

In this study, efficient synthesis of LNnT was achieved by optimizing the expression level of LgtA and LgtB and the modular optimization of two key precursors' synthesis pathway. The overexpression of $\operatorname{glm} M$ or $t u a D$ deletion was more useful to increase the production of LNnT than other genes in the synthesis of the two precursors, while the up-regulation of $g \operatorname{lm} U$ was not suitable in the LNnT-producing strain. The titer of LNnT was improved step-by-step from 0.05 to $1.95 \mathrm{~g} / \mathrm{L}$ in shake-flask culture, and $4.52 \mathrm{~g} / \mathrm{L}$ in a 3-L bioreactor by feed batch. In summary, this study demonstrated that the optimization of heterologous proteins expression level and modular engineering of synthetic pathways are feasible and effective for improving the synthesis of LNnT in B. subtilis. This strategy could also be useful for producing other valuable oligosaccharides.

\section{Supplementary information}

Supplementary information accompanies this paper at https://doi. org/10.1186/s13068-019-1551-3.

Additional file 1. Additional tables.

\begin{abstract}
Abbreviations
LNnT: lacto-N-neotetraose; LNTII: Lacto-N-triose II; UDP-GICNAc: UDP-N-acetyglucosamine; UDP-Gal: UDP-galactose; PEP: phosphoenolpyruvic acid; G6P: glucose-6-phosphate; F6P: fructose-6-phosphate; GICN-6-P: glucosamine6-phosphate; GlcN-1-P: glucosamine-1-phosphate; GlcNAc-1P: N-acetylglucosamine-1-phosphate; Glc-1P: glucose-1-phosphate; UDP-Glc: UDP-glucose; UDP-GICA: UDP-glucuronate; DCW: dry cell weight; PCR: polymerase chain reaction; $\mathrm{OD}_{600}$ : optical density at a wavelength of $600 \mathrm{~nm}$.
\end{abstract}

\section{Acknowledgements}

Not applicable.

\section{Authors' contributions}

XMD designed and performed the experiments. JHL and GCD analyzed the experiment data. $X M D, X Q L$, and $N L$ wrote the manuscript. $M W, L L$, and $Z M L$ refined the writing. All authors read and approved the final manuscript.

\section{Funding}

This work was financially supported by the National Natural Science Foundation of China (31622001, 31871784, 31870069, 21676119, and 31671845) and the Key Research and Development Program of China (2018YFA0900300).

\section{Availability of data and materials}

The data supporting the results of the article are included in this manuscript and additional files.

\section{Ethics approval and consent to participate}

Not applicable.

\section{Consent for publication}

Not applicable.

\section{Competing interests}

The authors declare that they have no competing interests.

\section{Author details}

${ }^{1}$ Key Laboratory of Food Science and Technology, Ministry of Education, Jiangnan University, Wuxi 214122, China. ${ }^{2}$ State Key Laboratory of Dairy Biotechnology, Shanghai Engineering Research Center of Dairy Biotechnology, Dairy Research Institute, Bright Dairy \& Food Co, Ltd, Shanghai 200436, China. ${ }^{3}$ Key Laboratory of Carbohydrate Chemistry and Biotechnology, Ministry of Education, Jiangnan University, Wuxi 214122, China. ${ }^{4}$ Key Laboratory of Industrial Biotechnology, Ministry of Education, Jiangnan University, Wuxi 214122, China.

Received: 5 June 2019 Accepted: 24 August 2019

Published online: 09 September 2019

\section{References}

1. Vandenplas Y, Berger B, Carnielli VP, Ksiazyk J, Lagstrom H, Sanchez LM, et al. Human milk oligosaccharides: $2^{\prime}$-fucosyllactose (2'-FL) and lacto-NNeotetraose (LNnT) in infant formula. Nutrients. 2018;10:1161.

2. Geralyn DM, Albert PS, Teah LR, Edward GB, Rachael HB. Human milk oligosaccharides enhance innate immunity to respiratory syncytial virus and influenza in vitro. FNS. 2014;5:1387-98.

3. Elison E, Vigsnaes LK, Krogsgaard LR, Rasmussen J, Sorensen N, McConnel $\mathrm{B}$, et al. Oral supplementation of healthy adults with $2^{\prime}$-O-fucosyllactose and lacto- $\mathrm{N}$-neotetraose is well tolerated and shifts the intestinal microbiota. Br J Nutr. 2016;116:1356-68.

4. James K, Motherway MOC, Bottacini F, Sinderen DV. Bifidobacterium breve UCC2003 metabolises the human milk oligosaccharides lacto-N-tetraose and lacto-N-neo-tetraose through overlapping, yet distinct pathways. Sci Rep. 2016;6:38560.

5. Ozcan E, Sela DA. Inefficient metabolism of the human milk oligosaccharides lacto- $N$-tetraose and lacto- $N$-neotetraose shifts Bifidobacterium longum subsp. infantis physiology. Front Nutr. 2018;5:46.

6. Bunesova V, Lacroix C, Schwab C. Fucosyllactose and L-fucose utilization of infant Bifidobacterium longum and Bifidobacterium kashiwanohense. Microbiol. 2016;16:248.

7. Duranti S, Lugli GA, Mancabelli L, Armanini F, Turroni F, James K, et al. Maternal inheritance of bifidobacterial communities and bifidophages in infants through vertical transmission. Microbiome. 2017;5:66.

8. Holscher HD, Davis SR, Tappenden KA. Human milk oligosaccharides influence maturation of human intestinal Caco-2Bbe and HT-29 cell lines. J Nutr. 2014;144:586-91.

9. Chen CC, Zhang Y, Xue M, Liu XW, Li Y, Chen X, et al. Sequential one-pot multienzyme (OPME) synthesis of lacto- $N$-neotetraose and its sialyl and fucosyl derivatives. Chem Commun (Camb). 2015;51:7689-92.

10. Bych K, Miks MH, Johanson T, Hederos MJ, Vigsnaes LK, Becker P. Production of HMOs using microbial hosts_-from cell engineering to large scale production. Curr Opin Biotechnol. 2019;56:130-7.

11. Priem B, Gilbert M, Wakarchuk WW, Heyraud A, Samain E. A new fermentation process allows large-scale production of human milk oligosaccharides by metabolically engineered bacteria. Glycobiology. 2002;12:235-40.

12. Earl AM, Losick R, Kolter R. Ecology and genomics of Bacillus subtilis. Trends Microbiol. 2008;16:269-75.

13. Liu YF, Link H, Liu L, Du GC, Chen J, Sauer U. A dynamic pathway analysis approach reveals a limiting futile cycle in $\mathrm{N}$-acetylglucosamine overproducing Bacillus subtilis. Nat Commun. 2016;7:11933.

14. Lu ZH, Yang SH, Yuan X, Shi YY, Ouyang L, Jiang SJ, et al. CRISPR-assisted multi-dimensional regulation for fine-tuning gene expression in Bacillus subtilis. Nucleic Acids Res. 2019;47:e40.

15. Nicolas P, Mader U, Dervyn E, Rochat T, Leduc A, Pigeonneau N, et al. Condition-dependent transcriptome reveals high-level regulatory architecture in Bacillus subtilis. Science. 2012;335:1103-6.

16. Wu YK, Chen TC, Liu YF, LV XQ, Li JH, Du GC, et al. CRISPRi allows optimal temporal control of $\mathrm{N}$-acetylglucosamine bioproduction by a dynamic coordination of glucose and xylose metabolism in Bacillus subtilis. Metab Eng. 2018;49:232-41. 
17. Wang CY, Cao YX, Wang YP, Sun LM, Song H. Enhancing surfactin production by using systematic CRISPRi repression to screen amino acid biosynthesis genes in Bacillus subtilis. Microb Cell Fact. 2019;1:90.

18. Yan X, Yu HJ, Hong Q, Li SP. Cre/lox system and PCR-based genome engineering in Bacillus subtilis. Appl Environ Microbiol. 2008;74:5556-62.

19. Zhang XZ, Zhang YHP. Simple, fast and high-efficiency transformation system for directed evolution of cellulase in Bacillus subtilis. Microb Biotechnol. 2011;4:98-105.

20. Li H. Extraction, purification, characterization and antioxidant activities of polysaccharides from Ramaria botrytis (Pers) Ricken. Chem Cent J. 2017;11:24.

21. Dumon C, Bosso C, Utille JP, Heyraud A, Samain E. Production of Lewis $x$ tetrasaccharides by metabolically engineered Escherichia coli. ChemBioChem. 2006;7:359-65

22. Ceroni F, Boo A, Furini S, Gorochowski TE, Borkowski O, Ladak YN, et al. Burden-driven feedback control of gene expression. Nat Methods. 2018;15:387-93.

23. Jin P, Kang Z, Yuan PH, Du GC, Chen J. Production of specific-molecularweight hyaluronan by metabolically engineered Bacillus subtilis 168 Metab Eng. 2016:35:21-30.
24. Liu YF, Zhu YQ, Li JH, Shin HD, Chen RR, Du GC, et al. Modular pathway engineering of Bacillus subtilis for improved $\mathrm{N}$-acetylglucosamine production. Metab Eng. 2014;23:42-52.

25. Zhang XL, Liu YF, Liu L, Wang M, Li JH, Du GC, et al. Modular pathway engineering of key carbon-precursor supply-pathways for improved $\mathrm{N}$-acetylneuraminic acid production in Bacillus subtilis. Biotechnol Bioeng. 2018;115:2217-31.

26. Esvelt KM, Carlson JC, Liu DR. A system for the continuous directed evolution of biomolecules. Nature. 2011:472:499-503.

27. Ma FQ, Chung MT, Yao Y, Nidetz R, Lee LM, Liu AP, et al. Efficient molecular evolution to generate enantioselective enzymes using a dual-channel microfluidic droplet screening platform. Nat Commun. 2018;9:1030.

\section{Publisher's Note}

Springer Nature remains neutral with regard to jurisdictional claims in published maps and institutional affiliations.
Ready to submit your research? Choose BMC and benefit from:

- fast, convenient online submission

- thorough peer review by experienced researchers in your field

- rapid publication on acceptance

- support for research data, including large and complex data types

- gold Open Access which fosters wider collaboration and increased citations

- maximum visibility for your research: over $100 \mathrm{M}$ website views per year

At $\mathrm{BMC}$, research is always in progress.

Learn more biomedcentral.com/submissions 